Original Research Article

\title{
A prospective study of adverse drug reactions in a tertiary care teaching hospital
}

\author{
More Pankaj Daulat ${ }^{1}$, Ambika Abhishake V. J. ${ }^{2 *}$, Prabhakar Singh ${ }^{3}$, Bhupendra Raj ${ }^{3}$
}

${ }^{1}$ Department of Pharmacology, SMBT IMS and RC,

Dhamangaon, Nashik,

Maharashtra, India

${ }^{2}$ Department of Pharmacology, DMWIMS Medical College, Meppadi, Wayanad, Kerala, India

${ }^{3}$ Department of Pharmacology, SSMC, Rewa, Madhya Pradesh, India

Received: 21 July 2018

Accepted: 29 August 2018

*Correspondence to:

Dr. Ambika Abhishake V. J,

Email: ambingu@gmail.com

Copyright: (C) the author(s), publisher and licensee Medip Academy. This is an openaccess article distributed under the terms of the Creative Commons Attribution NonCommercial License, which permits unrestricted noncommercial use, distribution, and reproduction in any medium, provided the original work is properly cited.

\begin{abstract}
Background: Adverse drug reactions (ADRs) have become frequent cause for hospitalization and are coming up as an economic burden on health systems. Identification of ADRs and their reporting pattern can provide useful information for their management.

Methods: This was an observational and prospective study. ADR reports of 130 patients were collected of the inpatient department of various clinical departments of Sanjay Gandhi Memorial Hospital, Rewa, Madhya Pradesh (M.P.) The ADRs were collected during October 2014-September 2015, with ADR reporting form of Central Drugs Standard Control Organization (CDSCO), New Delhi. ADRs were assessed for their causality, severity, and preventability as per the standard scales. Data was analysed using descriptive statistics and expresses in percentages.
\end{abstract}

Results: Overall occurrence of ADRs was slightly more in males (55\%). Maximum (26\%) suspected ADR reported during study period was skin rash. Skin $(44 \%)$ was the most commonly affected organ system. Antimicrobials (68\%) were the drug group most commonly involved in ADRs. Most of the suspected ADRs were probable in causality assessment, moderate in severity and probably preventable.

Conclusions: The study results revealed opportunities for interventions in ADR management to ensure safer drug use.

Keywords: Causality, Pharmacovigilance, Preventability, Severity

\section{INTRODUCTION}

Adverse Drug Reactions (ADRs) are fourth to sixth leading cause of death among hospitalized patients and it occurs in 0.3 percent to 7 percent of all hospital admissions. The incidence of serious ADRs is 6.7 percent. ${ }^{1}$ ADRs cause not only death and injury, but they also prolong the length of stay in hospitals which in turn leads to increased healthcare costs and decreased patient productivity. Alomar MJ et al, reported that there was $2.38 \%$ increase in the length of stay due to ADRs in intensive care units. ${ }^{2}$ As drug-related adverse events are estimated to cost USD 422-7062 per drug related admissions and USD 2284-5640 per inpatient with drugrelated adverse events, significant costs may be saved if drug-related adverse events, including ADRs, were prevented. ${ }^{3}$

ADRs monitoring and evaluating is a key component of effective drug regulation systems, clinical practice and public health programmes. ${ }^{4}$ The reporting of ADRs in hospitals is very important because innovative new drugs are usually used and severe ADRs are most likely to be 
seen in hospitals. ${ }^{5}$ Spontaneous reporting of ADRs, reported by healthcare workers is one of the most important methods of ADR detection. Under-reporting remains a major drawback of spontaneous reporting. It is estimated that only $6-10 \%$ of all ADRs are reported, this extremely low rate of reporting can delay signal detection and consequently impact negatively on the public health. ${ }^{6}$ Hence, this study was planned to evaluate pattern of suspected ADRs along with its causality, severity and preventability in a tertiary care teaching hospital.

\section{METHODS}

After obtaining approval and clearance from institutional ethics committee, total 130 ADR reporting forms of patients submitted to ADR monitoring centre of the institute were evaluated during the period October 2014September 2015.

These ADR forms were of the patients admitted in the various departments of Sanjay Gandhi Memorial Hospital, Rewa and Madhya Pradesh (M.P.). Following inclusion and exclusion criteria were applied for the recruitment of the participants.

\section{Inclusion criteria}

- Patients of all age groups and both genders with suspected ADRs,

- All suspected ADRs that confirms to WHO's definition and

- All patients with suspected ADRs admitted in ICU or ward.

\section{Exclusion criteria}

- Patients with reactions who have unclear drug history,

- Patients with drug reaction due to deliberate or unintentional over dosage or drug toxicity,

- Patients with associated ADR due to medicines of alternate systems like Ayurveda, Homeopathy, Siddha and Unani and

- Reactions occur due to blood and blood products.

The ADR reporting form of Central Drugs Standard Control Organization (CDSCO), New Delhi, India was used to collect information on ADRs. ${ }^{7}$ The form was distributed to all the departments. The health care providers were briefed about how to collect and record information on the ADR form. Health care providers reported ADRs to ADR monitoring centre of the Pharmacovigilance unit in the institute. The ADR monitoring centre personnel also visited all departments regularly to observe the ADRs and collect data.

Information of the patients including relevant history, examination details, investigations and drug therapy was collected and recorded in the CDSCO ADR form by visiting the patients daily till they were discharged from the hospital. When any other relevant information about ADR was required, the treating physicians were also contacted. Any untoward event was labelled as ADR as per WHO definition. ${ }^{8}$

A thorough clinical evaluation and scrutiny of data was done to assess pattern, extent, severity and duration of the reactions, to detect any predisposing or underlying disease/pathological factors, and to assess any other organ/ system involvement as a part of the drug reaction. The pattern of reported suspected ADRs was analysed. The causality was assessed with the help of Naranjo ADR probability scale and WHO-UMC causality categories. ${ }^{9,10}$ Severity was assessed by Modified Hartwig and Siegel Scale. ${ }^{11}$ Preventability was assessed by Modified Schumock and Thornton Scale. ${ }^{12}$ Data was analysed using descriptive statistics and expresses in percentages.

\section{RESULTS}

In this prospective study, total 130 ADR reports were collected. Gender distribution of the patients showed that there were $72(55.38 \%)$ male and $58(44.62 \%)$ female patients indicating male preponderance (Figure 1).

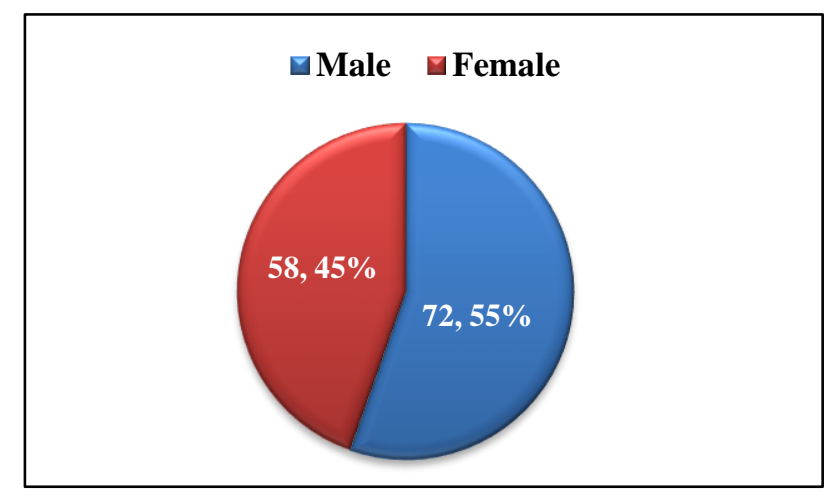

Figure 1: Gender wise distribution of study subjects $(n=130)$.

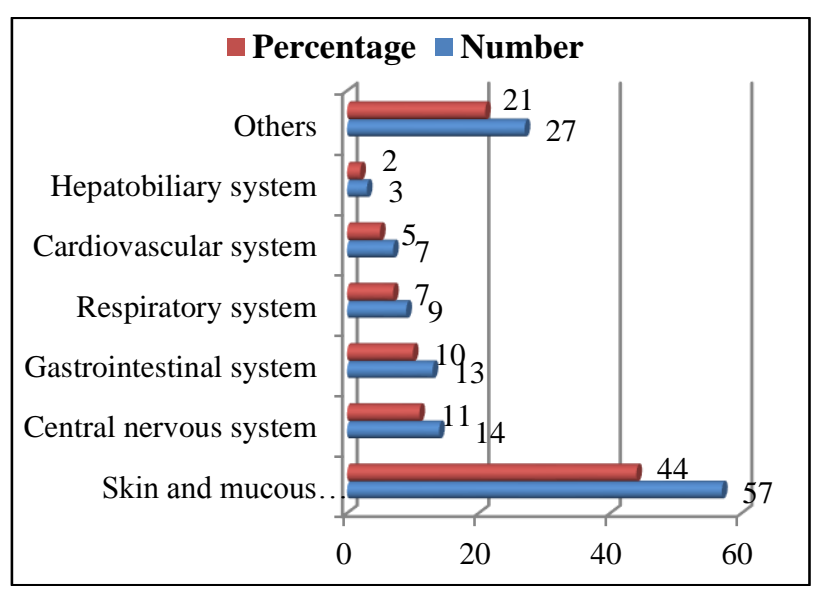

(Others include- tinnitus, visual disturbances, fever, rigor, weight gain, dryness of mouth, hair changes)

Figure 2: Frequency distribution of suspected ADRs according to organ system affected. 
The commonest organ system involved in ADRs was skin and mucous membrane accounting for $44 \%$ of total suspected ADR, followed by central nervous system $(11 \%)$, gastrointestinal system $(10 \%)$, respiratory system (7\%), cardiovascular system $(5 \%)$ and hepatobiliary system $(2 \%)$ in decreasing order. Others which include tinnitus, visual disturbances, fever, rigor, weight gain, dryness of mouth and hair changes accounting for $21 \%$ of total suspected ADRs (Figure 2).

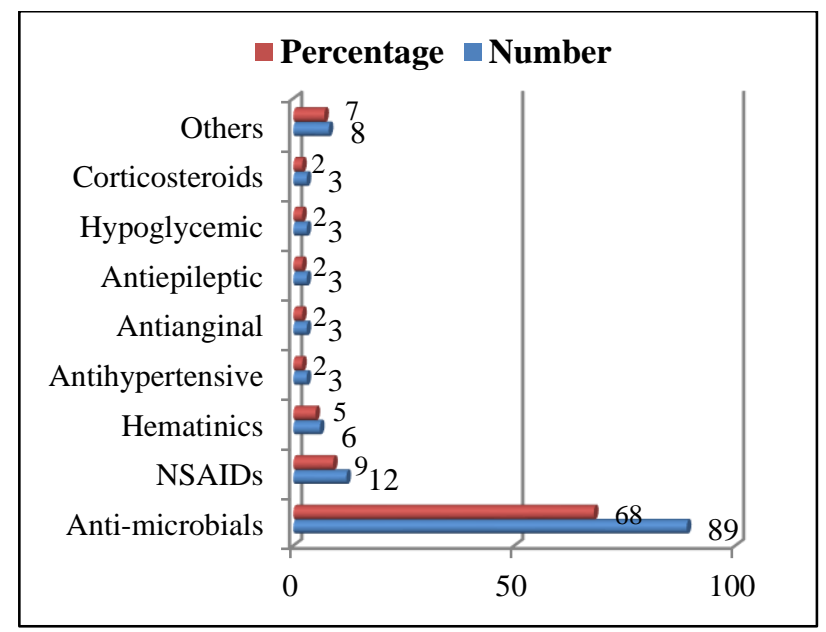

(Others include- Inotrops, Adrenergic, Antacids, Opioids,

Bronchodilators, Antihistaminics, Anticholinergic)

Figure 3: Frequency distribution of suspected ADRs according to therapeutic class of drugs.

Majority of suspected ADRs were associated with antimicrobials use in $68 \%$ of study participants, followed by NSAIDs (9\%) and hematinics (5\%). Antihypertensives, antianginals, antiepileptics, hypoglycemics and corticosteroids and ionotrops use each was associated with suspected ADRs in $2 \%$ of study participants. Adrenergics, antacids, opioids, bronchodialators, antihistaminics and anticholinergics each was associated with suspected ADRs in $1 \%$ of study participants (Figure 3 ).

Table 1: Causality assessment (WHO-UMC Causality Assessment Scale).

\begin{tabular}{|ll|}
\hline Causality assessment & $\begin{array}{l}\text { Frequency of cases } \\
(\%)\end{array}$ \\
\hline Certain & $4(3)$ \\
\hline Probable & $69(53)$ \\
\hline Posiible & $57(44)$ \\
\hline Unlikely & $0(0)$ \\
\hline Conditional/Unclassified & $0(0)$ \\
\hline Unassessable/Unclassifiable & $0(0)$ \\
\hline
\end{tabular}

According to WHO-UMC causality assessment, most of the ADRs were in the "probable" $(53 \%)$ category followed by "possible" (44\%) and "certain" (3\%) as shown in Table 1. Similarly, Table 2 shows the analysis with Naranjo algorithm-ADR probability scale revealing that majority of the ADRs were probable (52\%) followed by possible
(45\%) and definite (3\%). Severity assessment using Modified Hartwig and Siegel's scale showed that maximum ADRs were moderate (59\%), followed by mild $(37 \%)$ and Severe $(4 \%)$ as revealed in Table 3. Using Modified Schumock and Thornton preventability assessment scale, $90 \%$ of suspected ADRs were found to be probably preventable whereas $8 \%$ were definitely preventable but only $2 \%$ were not preventable (Table 4 ).

Table 2: Causality assessment (Naranjo's Probability Assessment Scale).

\begin{tabular}{|ll|}
\hline Causality assessment & Frequency of cases (\%) \\
\hline Certain & $4(3)$ \\
\hline Probable & $68(52)$ \\
\hline Posiible & $58(45)$ \\
\hline
\end{tabular}

Table 3: Severity assessment (Modified Hartwig and Siegel Scale).

\begin{tabular}{|ll|}
\hline Causality assessment & Frequency of cases (\%) \\
\hline Mild & $48(37)$ \\
\hline Moderate & $77(59)$ \\
\hline Severe & $5(4)$ \\
\hline
\end{tabular}

Table 4: Preventability assessment (Modified Schumock and Thornton Scale).

\begin{tabular}{|ll|}
\hline $\begin{array}{l}\text { Preventability } \\
\text { assessment }\end{array}$ & $\begin{array}{l}\text { Frequency of cases } \\
(\%)\end{array}$ \\
\hline Definitely preventable & $10(8)$ \\
\hline Probably preventable & $117(90)$ \\
\hline Not preventable & $3(2)$ \\
\hline
\end{tabular}

\section{DISCUSSION}

In the pharmacotherapy of various diseases, most of the drugs are likely to have a dual effect- beneficial as well as adverse. So, the best way to control these adverse effects is to have a triple pronged approach of prevention, treatment and rehabilitation.

Out of total 130 study participants, the mean age of patients was $34.84( \pm 20.99)$ years. Majority of the patients $(72 \%)$ were in the age group $19-59$ years. Gender distribution of the patients showed that there were 78 $(55 \%)$ male and $52(45 \%)$ female patients indicating higher incidence of suspected ADRs in males which was in consistence with earlier documented reports. ${ }^{13,14}$ The commonest suspected ADR was skin rash (26\%), which is in concordance with previous study, followed by pruritus $(15 \%) .{ }^{15}$

Serious ADRs are defined as ADRs that lead to death, congenital anomaly, disability, are life threatening, needs intervention to prevent permanent disability and prolongation of hospitalization. In present study, there were 3 reports of Steven Johnson Syndrome (SJS) and 2 reports of toxic epidermal necrosis (TEN), which were 
associated with commonly used drugs like diclofenac, moxifloxacin, nimesulide and ofloxacin, amoxicillin respectively. Hence, the clinicians should be more careful in observing these serious ADRs with these drugs. The commonest organ system involved in ADRs was skin and mucous membrane accounting for $44 \%$ of total suspected ADR which is consistent with previous studies. ${ }^{16-18}$ this was followed by involvement of Central nervous system in $11 \%$, gastrointestinal system in $10 \%$, respiratory system $7 \%$, cardiovascular system in 5\% and hepatobiliary system $2 \%$. Majority of suspected ADRs were associated with antimicrobials use in $68 \%$ of study participants which was consistent with previous studies, followed by NSAIDs $(9 \%) .{ }^{19-22}$

Ceftriaxone was the most common associated drug among the antimicrobials, while paracetamol and nimesulide were among the NSAIDs. This was probably because they were being most commonly prescribed drugs in authors' hospital. The majority (52-53\%) of ADRs were found to be probable, which was consistent with the observations of previous studies. ${ }^{23-24}$

There were some differences in assessment methods of the WHO-UMC and Naranjo's scale, this may be due to the former being subjective and the latter being more objective. The "certain" relatedness is rare these days as it is not ethical to re-challenge the patient with the same causative drug, hence the assessment infrequently goes to probable category. Most of the ADRs were moderately severe (59\%) and probably preventable (90\%), which was consistent with the findings of previous studies. ${ }^{25-26}$

Hospital-based monitoring of suspected ADRs are convenient studies but the main limitation of these studies is that they do not yield the exact incidence of suspected ADRs associated with a particular drug use. To conclude, pharmacovigilance unit in medical colleges shall be more active and functional so that the results of reported suspected ADRs in terms of casualty, severity and preventability can be communicated to all the stakeholders. Careful planning and monitoring of drug therapy shall prevent majority of ADRs.

\section{CONCLUSION}

ADR monitoring is the key component of effective drug regulation systems, clinical practice and public health programmes. The study results revealed opportunities for interventions in ADR management to ensure safer drug use.

\section{ACKNOWLEDGEMENTS}

Authors would like to thank Dr Jitendra Chaturvedi; Assistant Professor in the Department of Pharmacology; SSMC Rewa; for his guidance and support throughout the project.
Funding: No funding sources

Conflict of interest: None declared

Ethical approval: The study was approved by the Institutional Ethics Committee

\section{REFERENCES}

1. Lazarou J, Pomeranz BH, Corey PN. Incidence of adverse drug reactions in hospitalized patients: a meta-analysis of prospective studies. JAMA. 1998 Apr 15;279(15):1200-5.

2. Alomar MJ. Factors affecting the development of adverse drug reactions. Saudi Pharmaceut J. 2014 Apr 1;22(2):83-94.

3. Hakkarainen KM, Hedna K, Petzold M, Hägg S. Percentage of patients with preventable adverse drug reactions and preventability of adverse drug reactions-a meta-analysis. PloS One. 2012 Mar 15;7(3):e33236.

4. Jeetu G, Anusha G. Pharmacovigilance: a worldwide master key for drug safety monitoring. J Young Pharmacists. JYP. 2010 Jul;2(3):315.

5. Vallano A, Cereza G, Pedròs C, Agustí A, Danés I, Aguilera C, Arnau JM. Obstacles and solutions for spontaneous reporting of adverse drug reactions in the hospital. Br J Clin Pharmacol. 2005 Dec;60(6):653-8.

6. John LJ, Arifulla M, Cheriathu J, Sreedharan J. Reporting of adverse drug reactions: A study among Clinicians. J App Pharmaceut Sci. 2012 Jun 1;2(06):135-9.

7. Pharmacovigilance program of India. CDSCO. Ministry of Health and Family Welfare, Government of India. 2010. Available at: http://cdsco.nic.in/pharmacovigilance.htm. Accessed 9 November 2017.

8. World Health Organization. International drug monitoring: The role of the hospital. Geneva, Switzerland: World Health Organization. 1966.

9. Naranjo CA, Busto U, Sellers EM, Sandor P, Ruiz I, Roberts EA, et al. A method for estimating the probability of adverse drug reactions. Clin Pharmacol Ther. 1981;30(2):239-45.

10. The Use of the WHO-UMC System for Standardised Case Causality Assessment. Available at: http://www.who-umc. org

11. Hartwig SC, Siegel J, Schneider PJ. Preventability and severity assessment in reporting adverse drug reactions. Am J Health Sys Pharmacy. 1992 Sep 1;49(9):2229-32.

12. Schumock GT, Thornton JP. Focusing on the preventability of adverse drug reactions. Hospital Pharmacy. 1992 Jun;27(6):538.

13. Gupta R, Sheik A, Strachan D, Anderson HR. Increasing hospital admission for systemic allergies disorders in England: analysis of national admission data. Br Med J. 2003;327(7424):1142-3.

14. Chawla S, Kalra BS, Dharmshaktu P, Sahni P. Adverse drug reaction monitoring in a tertiary care teaching hospital. J Pharmacol Pharmacother. 2011;2(3):196-8. 
15. Arulmani R, Rajendran SD, Suresh B. Adverse drug reaction monitoring in a secondary care hospital in South India. Br J Clin Pharmacol. 2007;65(2):210-6.

16. Murphy BM, Frigo LC. Development, implementation, and results of a successful multidisciplinary adverse drug reaction reporting program in a university teaching hospital. Hospital Pharmacy. 1993 Dec;28(12):1199-204.

17. Glassen DC, Pestotnik SL, Evans RS, Burke JP. Computerised surveillance of adverse drug events in hospital patients. JAMA. 1991;266:2847-51.

18. Prosser TR, Kamysz PL. Multidisciplinary adverse drug reaction surveillance programme. Am J Hosp Pharm. 1990;47:1334-39.

19. Wester K, Jonnson AK, Spigset O, Druid H, Hagg S. Incidence of fatal adverse drug reactions: a population based study. Br J Clin Pharmacol. 2007;65(4):573-9.

20. Gor AP, Desai SV. Adverse drug reactions (ADR) in the inpatients of medicine department of a rural tertiary care teaching hospital and influence of pharmacovigilance in reporting ADR. Indian $\mathbf{J}$ Pharmacol. 2008;40(1):37-40.

21. Wester K, Trivedi HR, Shah BK, Tripathi CB. Adverse drug reaction in inpatient of internal medicine wards at a tertiary care hospital: a prospective cohort study. J Pharmacol Pharmacother. 2011;2(1):21-5.

22. Leape LL, Brennan TA, Laird N, Lawthers AG, Localio AR, Barnes BA. The nature of adverse events in hospitalized patients: results of Harvard medical practice study II. N Engl J Med. 1991;324(6):377-84.

23. Acharya $T$, Mehta D, Shah H, Dave J. Pharmacovigilance study of adverse cutaneous drug reactions in a tertiary care hospital. Nat J Physiol. Pharm Pharmacol. 2013;3:75-81.

24. Jha N, Bajracharya O, Namgyal T. Prevalence of adverse drug reactions with commonly prescribed drugs in different hospitals of Kathmandu valley. Kathmandu Univ Med J. 2007;5(4):504-10.

25. Palanisamy S, Kumaran KSGA, Rajasekaran A. A study on assessment, monitoring, and reporting of adverse drug reactions in Indian hospital. Asian $\mathbf{J}$ Pharm and Clin Res. 2011;4(3):112-6.

26. Avery AJ, Anderson C, Bond CM, Gifford A, Hannarord PC. Evaluation of patient reporting of adverse drug reactions to the UK 'Yellow Card Scheme': literature review, descriptive and qualitative analyses, and questionnaire surveys. Health Technol Assess. 2011;15(20):49-72.

Cite this article as: Daulat MP, Ambika AVJ, Singh P, Raj B. A prospective study of adverse drug reactions in a tertiary care teaching hospital. Int $\mathrm{J}$ Basic Clin Pharmacol 2018;7:1965-9. 